\title{
Regional convergence clubs in Europe: Identification and conditioning factors
}

\author{
Monika Bartkowska * Aleksandra Riedl ${ }^{\dagger}$
}

June 8, 2009

First draft, do not quote!

\begin{abstract}
A class of growth theories explains the formation of convergence clubs among economies by differences in certain initial conditions. So far, it has not been tested empirically whether these initial conditions are indeed responsible for the appearance of multiple steady state equilibria. In this paper we tackle this issue by considering data on 206 European regions' per capita income from 1990 to 2005 . We employ a novel regression based convergence test developed by Phillips and Sul (2007) that enables the endogenous determination of convergence clubs. As this method requires cross-section observations to be independent, we first apply a spatial filtering technique in order to remove the spatial component from the data. Results strongly support the existence of convergence clubs, indicating that European regions form five separate groups converging to their own steady state paths. Moreover, estimates from an ordered probit model reveal that the level of initial conditions, such as human capital and per capita income, plays a crucial role in determining the formation of convergence clubs among European regions.
\end{abstract}

Keywords: Club convergence hypothesis, conditioning factors, European regions, spatial filtering, log $t$ regression test, probit model

JEL classification: C23; O40; R11

\footnotetext{
*Institute for Economic Geography and GIScience, Vienna University of Economics and Business, Nordbergstrasse 15,4,A 1090 Wien, Austria; monika.bartkowska@wu.ac.at

${ }^{\dagger}$ Institute for Economic Geography and GIScience, Vienna University of Economics and Business, Nordbergstrasse 15,4,A 1090 Wien, Austria; aleksandra.riedl@wu.ac.at
} 


\section{Introduction}

A class of growth theories (see e.g., Azariadis and Drazen, 1990; Galor, 1996) shows that economies that are rather similar in their structural characteristics (e.g. production technology, preferences, government policies, etc.) may nevertheless converge to different steady state equilibria if they differ in their initial conditions. Accordingly, within a group of similar economies, a common balanced growth path can only be expected when their initial conditions are in the basin of attraction of the same steady state equilibrium - a phenomenon widely referred to as the club convergence hypothesis (Galor, 1996).

In seeking to test the club convergence hypothesis a lot of effort has been devoted to develop appropriate econometric tools. Hereby, a major problem arises, as it is hard to empirically distinguish club convergence from conditional convergence, where economies with identical structural characteristics converge to one another independent of their initial conditions (Solow, 1956). This problem is related to the difficulty to a priori choose grouping criteria that are not associated with steady state determinants as differences in the latter cause equilibria to differ as well (see e.g., Islam, 2003). Recently, an increasing amount of literature has emerged that is concerned with the identification of convergence clubs via endogenized grouping, i.e., by leaving factors unspecified that are responsible for the appearance of multiple steady states (see e.g., Quah, 1996a; Burkhauser et al., 1999; Bernard and Durlauf, 1995; Hobijn and Franses, 2000). ${ }^{1}$ In this strand of literature there is a basic consensus that the distribution of income per capita across economies displays convergence clubs rather than a common growth path. Interestingly, this phenomenon does not apply exclusively to heterogeneous samples such as economies across different continents, but has been observed in fairly integrated markets too, e.g. in Western Europe (see Corrado et al., 2005; Mora, 2005; Quah, 1996b).

Yet, even though methods of endogenous grouping can assess the existence of convergence clubs, they cannot offer any insights for policy makers. In particular, there has been no attempt to empirically verify whether the observed multiple steady states can in fact be explained by theories that generate the club convergence hypothesis. Answering this question might be of particular relevance for the European Union and its goal to reduce economic disparities across European regions. Specifically, based on the assumption that regional redistribution is necessary to compensate for the shocks imposed by increasing economic integration, 35.7\% of the EU budget for the years 2007-2013 will be spent on cohesion policy.

Against this background, the aim of this paper is to examine whether these initial factors - brought forward by a certain class of theoretical models (e.g. Azariadis and Drazen, 1990) - are the driving force behind the formation of club convergence in per capita incomes across European NUTS 2 regions ${ }^{2}$. Our approach is most closely related to the paper by Corrado et al. (2005) who, in a first step, endogenously determine convergence

\footnotetext{
${ }^{1}$ Basically, this has been approached by two different methods including the distribution approach based on kernel density estimation (Quah, 1996a) and the time series approach relying on the concept of cointegration (Hobijn and Franses, 2000; Bernard and Durlauf, 1995).

${ }^{2}$ NUTS 2 (Nomenclature of Territorial Units for Statistics) is the European classification of regions which serves as a basis for the redistribution of structural funds.
} 
clubs in per capita income across European NUTS 1 regions by means of cointegration tests based on the method developed by Hobijn and Franses (2000). Subsequently they perform a multivariate cluster correlation analysis to describe the observed cluster patterns. Our analysis deviates from their approach in two important aspects. First, we employ a novel regression based convergence test developed by Phillips and Sul (2007), henceforth $\log t$ test, which provides a more suitable framework for analyzing convergence (see section 2.1 and Phillips and Sul, 2007, p.1779). In particular, it allows to endogenously reveal a broad spectrum of transitional behavior among economies, such as convergence to a common steady state, divergence and club convergence. As this test requires that the observations have to be independent across sample units, we use spatial filtering techniques (Getis, 1995) to remove the spatial component inherent in regional data on per capita incomes. Second, rather than describing the observed convergence clubs, we employ an ordered regression model to analyze the relative importance of different growth determinants. This allows us to distinguish between the role of structural characteristics and initial conditions. Amongst others, we test whether regions belonging to distinct convergence clubs also differ in their initial levels of human capital and per capita income, as was put forward by Azariadis and Drazen (1990).

Employing data on per capita income of 206 NUTS 2 regions in the period from 1990 to 2005, we find that European regions form five separate groups converging to their own steady state paths. Moreover, by controlling for the structural characteristics of regions, we show that a region's initial level of human capital and per capita income can indeed explain to which club it will converge. We also can confirm that differences in initial factor endowments are responsible for the multiplicity of steady state equilibria. This is in accordance with a slightly modified version of the neoclassical growth model, as was shown in Galor (1996).

The remainder of the paper is structured as follows. In section 2 we describe the method used to identify convergence clubs and provide the corresponding cluster results. In section 3 we discuss the main factors explored by growth literature that potentially determine the formation of convergence clubs and test their empirical relevance by means of an ordered regression model. Section 4 concludes.

\section{Club identification}

\subsection{A regression based convergence test}

In order to analyze the transitional behavior of per capita income among European regions over the 1990-2005 period we apply a regression based convergence test, developed by Phillips and Sul (2007). The test is based on an innovative decomposition of the variable of interest. Usually panel data are decomposed in the following way:

$$
\log y_{i t}=\varphi_{i} \mu_{t}+\epsilon_{i t}
$$


where $\varphi_{i}$ represents the unit characteristic component, $\mu_{t}$ the common factor and $\epsilon_{i t}$ the error term. In contrast, in the specification applied here, $\log$ of income per worker, $\log y_{i t}$, has a time varying factor representation that can be derived from the conventional panel data representation:

$$
\log y_{i t}=\left(\varphi_{i}+\frac{\epsilon_{i t}}{\mu_{t}}\right) \mu_{t}=\delta_{i t} \mu_{t}
$$

where $\delta_{i t}$ absorbs the error term and the unit specific component and therefore represents the idiosyncratic part that is varying over time. While the first model attempts to explain the behavior of the individual $\log y_{i t}$ by the common factor $\mu_{t}$ and two unit characteristic components, $\varphi_{i}$ and $\epsilon_{i t}$, the second approach seeks to describe income per worker by measuring the share $\left(\delta_{i t}\right)$ of the common growth path $\left(\mu_{t}\right)$ that economy $i$ undergoes. In order to model the transition coefficients $\delta_{i t}$, a relative transition coefficient, $h_{i t}$, is constructed:

$$
h_{i t}=\frac{\log y_{i t}}{N^{-1} \sum_{i=1}^{N} \log y_{i t}}=\frac{\delta_{i t}}{N^{-1} \sum_{i=1}^{N} \delta_{i t}}
$$

such that the common growth path is eliminated. Hence, $h_{i t}$ represents the transition path of the economy $i$ relative to the cross-section average and has a twofold interpretation: first, it measures the individual behavior in relation to other economies, and second, describes the relative departures of the economy $i$ from the common growth path $\mu_{t}$. In case of convergence, i.e., when all economies move towards the same transition path, $h_{i t} \rightarrow 1$ for all $i$ as $t \rightarrow \infty$. Then, the cross-sectional variance of $h_{i t}$, denoted by $V_{t}^{2}=N^{-1} \sum\left(h_{i t}-1\right)^{2}$, converges to zero. In case of no convergence there is a number of possible outcomes, i.e., $V_{t}$ may converge to a positive number, which is typical for club convergence, remain bounded above zero and not converge or diverge.

In order to specify the null hypothesis of convergence, Phillips and Sul (2007) model $\delta_{i t}$ in a semiparametric form:

$$
\delta_{i t}=\delta_{i}+\frac{\sigma_{i} \xi_{i t}}{L(t) t^{\alpha}}
$$

where $\delta_{i}$ is fixed, $\sigma_{i}$ is an idiosyncratic scale parameter ${ }^{3}, \xi_{i t}$ is $\operatorname{iid}(0,1), L(t)$ is a slowly varying function (such that $L(t) \rightarrow \infty$ as $t \rightarrow \infty$ ) and $\alpha$ is the decay rate.

The null hypothesis of convergence can be written as:

$$
H_{0}: \delta_{i}=\delta \text { and } \alpha \geq 0
$$

and it is tested against the alternative $H_{A}: \delta_{i} \neq \delta$ for all $i$ or $\alpha<0$. Note that under the null hypothesis of convergence various transitional patterns of economies $i$ and $j$ are possible, including temporary divergence and heterogeneity, meaning periods where $\delta_{i} \neq$ $\delta_{j}$. Hence, the method by Phillips and Sul (2007) enables to detect convergence even in case of transitional divergence, where other methods such as stationarity tests (see e.g. Hobijn and Franses, 2000) fail. In particular, stationary time series methods are unable to detect the asymptotic comovement of two time series and therefore erroneously reject the convergence hypothesis. ${ }^{4}$

\footnotetext{
${ }^{3}$ For details on regularity conditions concerning $\sigma_{i}$ and $\xi_{i t}$ see Phillips and Sul (2007), pp. 1786-1787.

${ }^{4}$ For details see Phillips and Sul (2007), pp. 1778-1780.
} 
To test for convergence, Phillips and Sul (2007) suggest the following procedure: first, the cross-sectional variance ratio $V_{1}^{2} / V_{t}^{2}$ is constructed and the $\log t$ regression is run:

$$
\begin{array}{r}
\log \left(\frac{V_{1}^{2}}{V_{t}^{2}}\right)-2 \log L(t)=a+b \log t+u_{t} \\
\text { for } t=[r T],[r T]+1, \ldots, T
\end{array}
$$

where in general $r \in(0,1)$ and $L(t)$ is a slowly varying function. Based on Monte Carlo simulations, Phillips and Sul (2007) suggest using $L(t)=\log t$ and $r=0.3$ for sample sizes beneath $T=50$. Finally, using $\hat{b}=2 \widehat{\alpha}$, a heteroscedasticity and autocorrelation (HAC) robust one sided $t$-test is applied to test the inequality of the null hypothesis $\alpha \geq 0$. The null hypothesis of convergence is rejected if $t_{\hat{b}}<-1.65$ ( $5 \%$ significance level).

If convergence is rejected for the overall sample, the testing procedure is applied to subgroups following a clustering mechanism test procedure suggested in Phillips and Sul (2007). The test consists of four steps, which are shortly described below (for the exact description see appendix A.2). First, the units are sorted in the descending order due to the last period in the time series dimension of the panel. Then, by means of the $\log t$ test the core group of a club and a convergence club is formed, if the $t_{\hat{b}}$ for this group is larger than -1.65 . Next, the $\log t$ test is repeated for all the units remaining in the sample to check whether they converge. If not, the first three steps are applied to the remaining units. If no convergence clubs are found, conclude that those units diverge.

\section{$2.2 \quad$ Spatial filtering approach}

Before applying the regression test for convergence we filter the data to eliminate the spatial components by applying the Getis' filter (Getis, 1995; Getis and Griffith, 2002). ${ }^{5}$ As borders of the NUTS 2 regions are not equal to the borders of the economic activities characteristic for every region, we expect per capita income, proxied by Gross Value Added (GVA) per worker, to exhibit spatial autocorrelation. Indeed, the Morans' $I$ test statistic for the year 2005 is equal to 0.6, indicating high spatial dependence in the variable of interest (see e.g. Anselin, 1988).

According to Getis' filtering procedure the spatially dependent variable — log GVA per worker - is divided into a filtered nonspatial variable and a residual spatial variable. First, distance $d$ has to be identified for which the $G_{i}$ statistic stops increasing and starts decreasing. At this point the limit on spatial autocorrelation is assumed to have been reached and the critical $d$ value is found. The filtered observation has the form:

$$
y_{i}=\frac{y_{i}\left[W_{i} /(n-1)\right]}{G_{i}(d)}
$$

where $y_{i}$ is the original variable, $W_{i}$ is the sum of all geographic connections $w_{i j}$ with ones for every connection between unit $i$ and unit $j$ within $d$ (and $i \neq j$ ), $n$ denotes the number

\footnotetext{
${ }^{5}$ Note that, before we apply the spatial filtering procedure, we first filter the data to remove the business cycle by means of the Hodrick-Prescott smoothing filter (Hodrick and Prescott, 1997), as suggested by Phillips and Sul (2007).
} 
of observations in the sample and $G_{i}(d)$ is the spatial autocorrelation statistic by Getis and Ord (1992):

$$
G_{i}(d)=\frac{\sum_{j} w_{i j}(d) y_{j}}{\sum_{j} y_{j}}, \quad i \neq j
$$

The data is filtered annually, i.e., the distances maximizing the $G_{i}$ statistic vary over the time span.

\section{$2.3 \quad$ Regional convergence clubs}

When applying the $\log t$ convergence test ${ }^{6}$ to the log of GVA per worker across $206 \mathrm{Eu}$ ropean NUTS 2 regions over the 1990-2005 period, the hypothesis of overall convergence is rejected at the 5\% significance level. Hence, we can conclude that European regions do not converge to the same steady state equilibrium concerning their GVA per worker. Therefore, we proceed to the clustering mechanism test procedure, where we identify 10 clusters and three diverging regions. Finally, to test whether any of the original subgroups can be merged to form larger convergence clubs, we apply the merging test procedure outlined in the appendix A.3. After a further pass through the data five clubs are found. The results are presented in table 1, where we report the estimated parameters, the corresponding standard errors of the convergence test and the average GVA per worker in thousand Euro for the year 2005. Moreover, we visualize the club membership in figure 1.

Table 1: Convergence club classification

\begin{tabular}{lcccc}
\hline \hline Club & Number of regions & $\widehat{b}$ & s.e. & GVA pw \\
\hline Club 1 & 33 & -0.1874 & $(0.1207)$ & 64 \\
Club 2 & 111 & -0.1238 & $(0.0841)$ & 48 \\
Club 3 & 40 & -0.0383 & $(0.0663)$ & 40 \\
Club 4 & 19 & 0.0471 & $(0.1639)$ & 30 \\
Club 5 & 3 & 0.4299 & $(0.0673)$ & 18 \\
\hline \hline
\end{tabular}

There are a few regularities visible in the obtained European convergence clubs. First, there is an apparent country effect, i.e., regions belonging to the same country tend to cluster together (see Barro and Sala-i-Martin, 1991 and Quah, 1996a). This applies most notably for Switzerland, but also for Austria, France and the Netherlands. Second, regions including capital cities of the respective country appear to belong to a higher club than the neighboring regions, see for example Attiki (including Athens), Île de France (including Paris), Inner London, Lisbon or Vienna. This could be due to agglomeration effects, as presented for example by Martin and Ottaviano (2001).

Interestingly, the club formation seems to be spatially concentrated, that is regions belonging to the same club tend to cluster together. This is confirmed by the Moran's $I$ test statistic equal to 0.5, when applied to the club category variable. Given that the data was spatially filtered before applying the convergence test, the spatial dependence among

\footnotetext{
${ }^{6}$ The $\log t$ convergence test, the clustering mechanism test procedure and the Getis' filter are programmed in Matlab. The codes are available upon request from the authors.
} 
the clubs is likely to be of substantive nature. In particular, it could be driven by factors like informational externalities or knowledge spillovers (Quah, 1996a).

The influence of cohesion funds on the club membership is ambiguous. On the one hand, there are regions that have received cohesion funds and remain in the fourth and fifth club, like regions from Southern Europe (e.g. Greece, Portugal and Spain). This seems to be consistent with Dall'erba and Le Gallo (2008) who find no significant impact of structural funds on the economic performance of regions. On the other hand however, some initially poor regions have managed a take-off and now belong to the first club, like Attiki or South and Eastern Ireland. This visual, loose analysis is supplemented by a more formal investigation in section 3.2 .

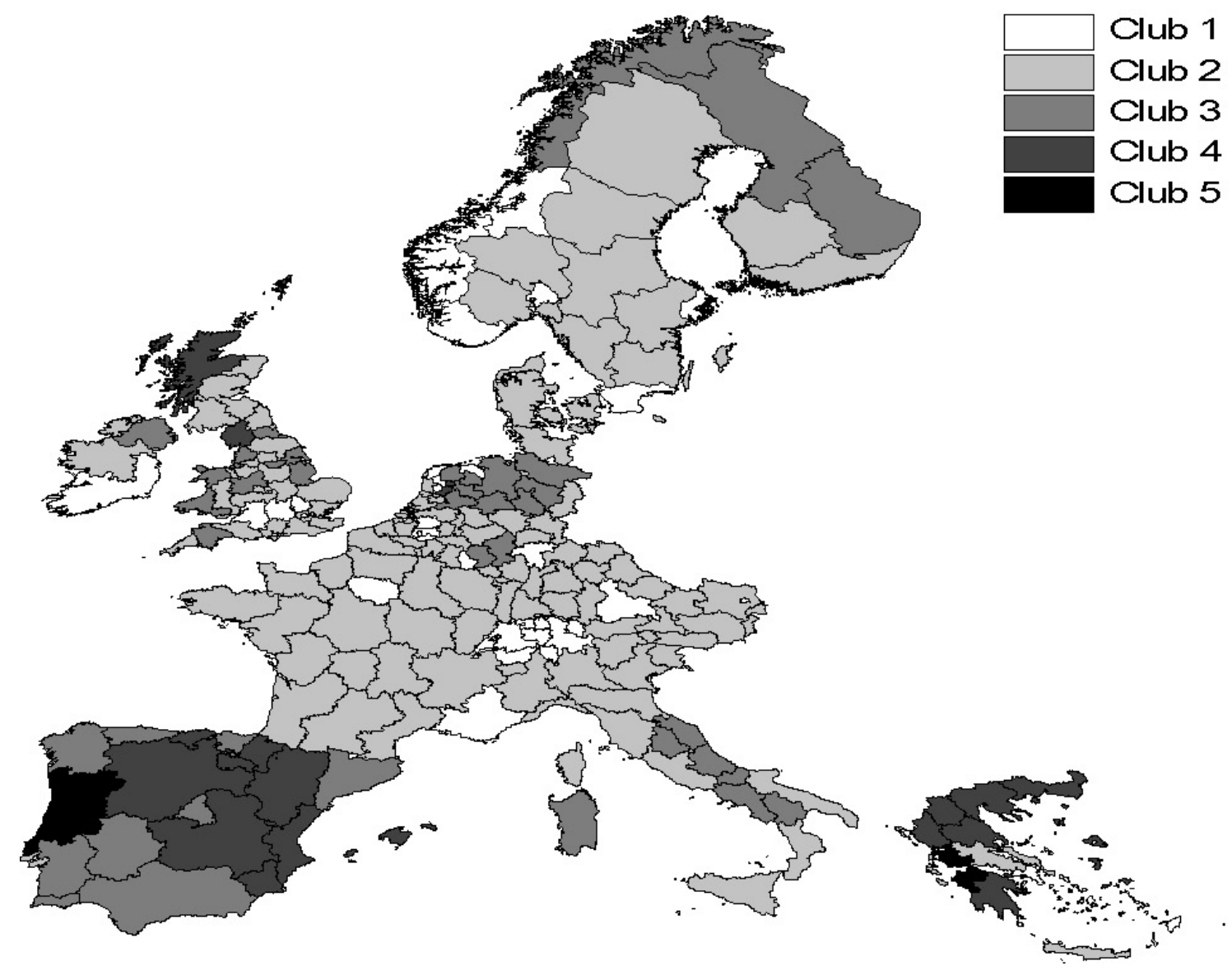

Figure 1: Clubs

Next, we employ a test to explore development tendencies between the groups. By means of the $\log t$ test we check whether the $\lambda_{1}$ fraction of the lower income members in the upper club and the $\lambda_{2}$ fraction of the higher income members in the lower club converge. We set $\lambda_{1}=\lambda_{2}=0.5$. The test for convergence between the subsequent clubs does not allow to reject the convergence hypothesis for any of the pairs. There is an ambiguity concerning the interpretation of such a result. First, it could indicate that regions now belonging to different clubs are only slowly converging towards each other. However, the transition paths of the five clubs displayed in figure 2 do not seem to confirm such a presumption. After getting closer in the mid 1990s, the transition paths appear 
to move away from each other. Second, it could simply point to rather blurred borders between the clubs, as some regions might already be in transition towards a higher or a lower club. The latter reasoning looks more plausible concerning the short time span used in the study. Interestingly, Phillips and Sul (2009) find similar results in analyzing the transitional behavior of per capita income of 152 countries from 1970 to 2003.

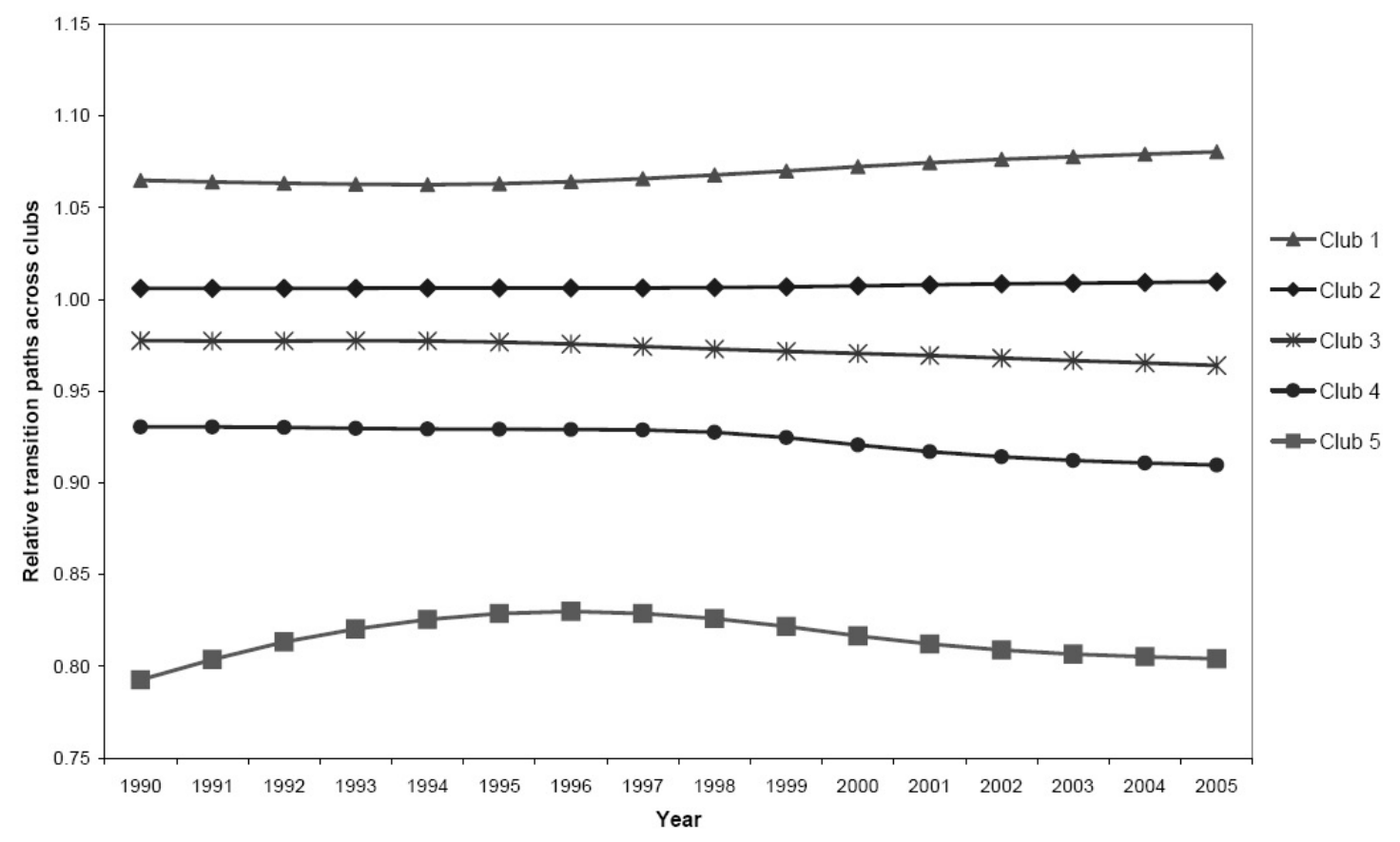

Figure 2: Transition paths

\section{Factors conditioning club formation}

\subsection{Theoretical considerations and data}

According to the club convergence hypothesis, economies that exhibit identical structural characteristics converge to one another, only if they face the same initial conditions (see Galor, 1996). In this section we discuss the main factors explored by growth literature that potentially determine the formation of convergence clubs. That is, we focus on the initial conditions that are crucial in determining the growth path of an economy, but also consider important structural characteristics of an economy to properly identify the former. Furthermore, we discuss indicators to measure these factors as they will be employed in the next subsection to empirically assess whether theory can actually explain the observed convergence patterns of European regions.

Theoretical contributions to growth theory identify several initial factors that can be decisive for the determination of the long-run steady state path. ${ }^{7}$ In the neoclassical framework (Solow, 1956), heterogeneity in factor endowments can explain the emergence of multiple steady state equilibria. In particular, if savings occur only out of wages the

\footnotetext{
${ }^{7}$ See Galor (1996) for a comprehensive overview on theoretical models explaining convergence clubs.
} 
initial level of the capital-labor ratio can determine which steady state is approached by the economy (Galor, 1996; Deardorff, 2001). In order to control for differences in factor endowments across regions we employ a labor force variable and use investment data to measure the capital stock of a region. Moreover, to additionally reflect the relative importance of factors in production across regions we proxy differences in factor intensities by the capital share. Table 2 provides the definition of the variables and the corresponding sources.

Azariadis and Drazen (1990) augment the neoclassical growth model by incorporating threshold externalities in the accumulation of human capital that can induce multiple balanced growth paths as stationary equilibria. Specifically, due to increasing social returns to scale that become particularly pronounced when the stock of knowledge attains critical mass values, the initial conditions with respect to human capital accumulation may determine the growth path of an economy. In particular, the authors argue that rapid growth can only occur with a relatively overqualified labor force, i.e., a high level of human investment relative to per capita income. To test this presumption, we use the educational attainment of the working-age population as a proxy for human capital as well as GVA per worker as a measure for per capita income.

To identify the net impact of the initial factors on the formation of convergence clubs, we consider indicators that control for an economy's structural characteristics. A particularly relevant and often considered prerequisite for a common steady state growth path of economies is a similar production technology (see for example Galor, 1996). To control for differences in production technologies across regions we employ the share of high-tech production to total service and manufacturing production by relying on the OECD classification of technology- and knowledge-intensive sectors (see also Mora, 2008). Additionally, we consider the industrial structure of a region by employing GVA in the service sector as a share of total GVA.

Quah (1996a) points to the importance of informational externalities for explaining the club convergence phenomenon. These externalities may occur either at the state or the neighborhood level as information is likely to flow more easily across regions that belong to the same state or share a border. Indeed, as already discussed in section 2.3 (see also Fig.1), European regions belonging to the same country seem to form a common convergence club. Also, as reflected by the value of the Moran's I statistic (i.e., 0.5, see section 2.3), nearby regions tend to cluster together, indicating that physical location and geographical spillovers are relevant for the convergence process of European regions. In order to capture this form of externality we employ two different indicators. First, we use country dummies to control for country membership. Second, we consider the output per capita of neighboring regions to control for geographical spillovers. The idea is that the economic activity of a bordering region should influence the own region's economy and therefore have an impact on the own regions's convergence process. More specifically, we use the spatial lag of GVA per worker, where we apply a contiguity weighting matrix $(W)$ of order one, i.e., regions sharing a border are defined to be neighbors. ${ }^{8}$

\footnotetext{
${ }^{8}$ Note that the neighbor of islands is the region which is the closest in terms of geographical distance.
} 
Table 2: Variables and Sources

\begin{tabular}{|c|c|c|}
\hline Variable & Definition & Source \\
\hline \multicolumn{3}{|l|}{ Initial conditions } \\
\hline Labor force & $\begin{array}{l}\text { Active population as a share of total popula- } \\
\text { tion: } 1990\end{array}$ & $\begin{array}{l}\text { Cambridge Econo- } \\
\text { metrics Database } \\
(\mathrm{CED})\end{array}$ \\
\hline Capital stock & $\begin{array}{l}\text { Own calculation using the perpetual inven- } \\
\text { tory method by assuming a depreciation rate } \\
\text { of } 10 \% \text { based on investment data from 1980- } \\
\text { 1990, in logs: } 1990\end{array}$ & CED \\
\hline Capital share & $\begin{array}{l}\text { GVA minus compensation to employees, di- } \\
\text { vided by nominal value added: } 1990\end{array}$ & CED \\
\hline Human capital & $\begin{array}{l}\text { Population with higher education ( } 5 \text { and } 6 \\
\text { ISCED) as a share of population older than } \\
\text { 14: } 1995\end{array}$ & $\begin{array}{l}\text { Labor Force Sur- } \\
\text { vey }\end{array}$ \\
\hline Income per capita & $\begin{array}{l}\text { GVA divided by worker, constant prices, in } \\
\text { logs: } 1990\end{array}$ & CED \\
\hline \multicolumn{3}{|c|}{ Structural characteristics } \\
\hline High-tech production & $\begin{array}{l}\text { GVA in high-tech manufacturing and services } \\
\text { divided by GVA in total manufacturing and } \\
\text { services: 1990; High-tech manufacturing sec- } \\
\text { tors refer to: Fuels, chemicals, rubber and } \\
\text { plastic products and Electronics; High-tech } \\
\text { service sectors refer to: Transport and Com- } \\
\text { munications and Financial services }\end{array}$ & CED \\
\hline Services & $\begin{array}{l}\text { GVA in the service sector as a share of to- } \\
\text { tal:1990 GVA }\end{array}$ & CED \\
\hline Population growth & $\begin{array}{l}\text { Growth rate of total population between } 1980 \\
\text { and } 1990\end{array}$ & CED \\
\hline Country membership & $\begin{array}{l}\text { Dummy variable for regions belonging to the } \\
\text { same country }\end{array}$ & own calculation \\
\hline$W$ GVA per worker & $\begin{array}{l}W \text { multiplied by GVA per worker (as de- } \\
\text { fined above), where } W \text { refers to a standard- } \\
\text { ized contiguity weighting matrix of order one: } \\
1990\end{array}$ & own calculation \\
\hline Agglomeration & Population density: 1990 & CED \\
\hline
\end{tabular}

Also Barro and Sala-i-Martin (1991) argue that convergence is more likely amongst regions within a country than amongst regions situated in different countries because institutional frameworks, regulatory systems, consumer tastes and technologies are more similar within a country than between different countries. As we consider country dummies we are able to account for these country specific factors as well.

An important growth determinant in neoclassical models is the rate of population growth, which we also include in our set of explanatory variables (Mora, 2008). Finally, as geographical agglomeration of economic activities may reinforce economic growth, we add 
population density to our set of explanatory variables to control for agglomerated regions (see e.g. Corrado et al., 2005; Martin and Ottaviano, 2001).

\subsection{Results from an ordered probit model}

In order to explain the formation of convergence clubs across European regions we employ an ordered regression model, first introduced by McKelvey and Zavoina (1975). The variable to be explained, denoted by $c$, indicates the club a region belongs to according to the endogenized grouping procedures outlined in section 2.1. As the fifth club consists of only three regions we pool club 4 and club 5 to one single club, such that $c$ takes on values from 1 to 4 . This variable can be classified as an ordinal variable since the observed clubs can be ranked according to the steady state per capita income levels of regions in the respective club but the differences between steady state levels across clubs are not known. For example, regions belonging to the first club move to a higher income steady state level than regions belonging to the remaining clubs. Assuming that the membership in a certain club is related to a continuous, latent variable $y_{i}^{*}$ that indicates a region's individual steady state income level, the model can be written as,

$$
y_{i}^{*}=X_{i} \beta+\epsilon_{i}
$$

where $X_{i}$ contains the explanatory variables (in the initial period) listed in table 2 as well as a constant term, with $i=1, \ldots, 206$ indicating the region. The column vector $\beta$ includes the structural coefficients. As the dependent variable $y_{i}^{*}$ is unobserved, the model cannot be estimated with OLS, but instead Maximum Likelihood (ML) techniques are applied to compute the probabilities of observing values of $c$ given $X$ (ordered regression model). In order to use ML, the distribution of the error term $\epsilon_{i}$ has to be specified. As is convenient, we assume the errors to be normally distributed with mean 0 and variance 1 , such that the resulting ordered regression model can be referred to as probit model. Since the latter is non-linear in the probability outcomes, the impact of a variable on the outcomes can be interpreted in various ways. In order to explore the effect of a single variable on the probability of belonging to a specific club, we follow the literature and report marginal effects on probabilities of each variable evaluated at its mean and at the mean of all the other explanatory variables. Furthermore, as we are particularly interested in the influence of the initial conditions on the formation of convergence clubs, we display the entire probability curve of each of the initial conditioning variables (given they are significant) by holding the remaining variables constant. Hence, we can observe the probabilities of belonging to a certain club depending on the level of the corresponding variable. ${ }^{9}$

In table 3.2 we report marginal effects for each outcome of the club variable $c$. At the bottom of the table we display the number of regions belonging to a particular club,

\footnotetext{
${ }^{9}$ For an overview on ordered probit models, see e.g., Greene (2000) and Long (1997). Estimation was done by using the command oprobit in Stata.
} 
Table 3: Marginal Effects on Probabilities

\begin{tabular}{lcclr}
\hline \hline Variable & Club 1 & Club 2 & Club 3 & Club 4 \& 5 \\
\hline & & & & \\
Initial conditions & & & & \\
Labor force & $0.498^{* *}$ & $1.240^{* * *}$ & $-1.653^{* * *}$ & -0.085 \\
& $(0.207)$ & $(0.462)$ & $(0.525)$ & $(0.057)$ \\
Capital stock & 0.031 & 0.077 & -0.102 & -0.005 \\
& $(0.030)$ & $(0.075)$ & $(0.097)$ & $(0.006)$ \\
Capital share & $0.189^{*}$ & $0.471^{*}$ & $-0.628^{*}$ & -0.032 \\
& $(0.116)$ & $(0.259)$ & $(0.329)$ & $(0.026)$ \\
Human capital & $0.004^{*}$ & $0.011^{*}$ & $-0.014^{* *}$ & -0.001 \\
& $(0.002)$ & $(0.006)$ & $(0.007)$ & $(0.001)$ \\
Income per capita & $0.244^{* *}$ & $0.609^{* * *}$ & $-0.811^{* * *}$ & -0.042 \\
& $(0.099)$ & $(0.213)$ & $(0.240)$ & $(0.027)$ \\
Structural characteristics & & & \\
Services & $0.309^{* *}$ & $0.770^{* *}$ & $-1.026^{* * *}$ & -0.053 \\
High-tech & $(0.138)$ & $(0.314)$ & $(0.369)$ & $(0.036)$ \\
& $0.492^{* *}$ & $1.227^{* *}$ & $-1.635^{* * *}$ & -0.084 \\
Population growth & $(0.229)$ & $(0.506)$ & $(0.601)$ & $(0.058)$ \\
& 9.496 & $23.658^{*}$ & $-31.528^{*}$ & -1.626 \\
Agglomeration & $(5.449)$ & $(13.097)$ & $(16.25)$ & $(1.261)$ \\
& 0.013 & 0.032 & -0.043 & -0.002 \\
W GVA per capita & $(0.016)$ & $(0.037)$ & $(0.049)$ & $(0.003)$ \\
& $-0.132^{* *}$ & $-0.330^{* *}$ & $0.439^{* *}$ & 0.023 \\
& $(0.068)$ & $(0.162)$ & $(0.196)$ & $(0.017)$ \\
\hline Number of regions & 33 & 111 & 40 & 22 \\
Country dummies & yes & yes & yes & yes \\
\hline \hline
\end{tabular}

Significance levels : $\quad *: 10 \% \quad * *: 5 \% \quad * * *: 1 \%$

Notes: As common in the literature, the presented marginal effects are computed at the mean of all variables as an approximation for the average marginal effects. Country dummies are included but not reported for brevity. Standard errors are reported in parentheses.

where the last line indicates the inclusion of country dummies (not reported for brevity). ${ }^{10}$ The individual partial derivatives indicate the change in the probability of belonging to a specific club, given a small change in the explanatory variables. Given this, the probability of being a member in the first three clubs is quite well explained by the chosen variables, while this does not hold for the last club, including the 22 least developed regions. This might be due to the fact that the sample size is extremely low, such that most of the effects are only significant at the $20 \%$ level. Yet, looking at the first three columns a clear picture arises. Apart from the capital stock variable, all initial conditions play a significant role in explaining a region's membership to a specific club. In particular, a small positive change in these variables raises the probability of belonging to a high-income club (club 1 and

\footnotetext{
${ }^{10}$ Note that we only include significant country dummies, i.e., dummies for the UK, Germany, Spain, the Netherlands and Finland. They were selected according to a drop down procedure, where we first estimated the model including all dummies and then dropped the insignificant ones (lowest t-value) one at a time.
} 

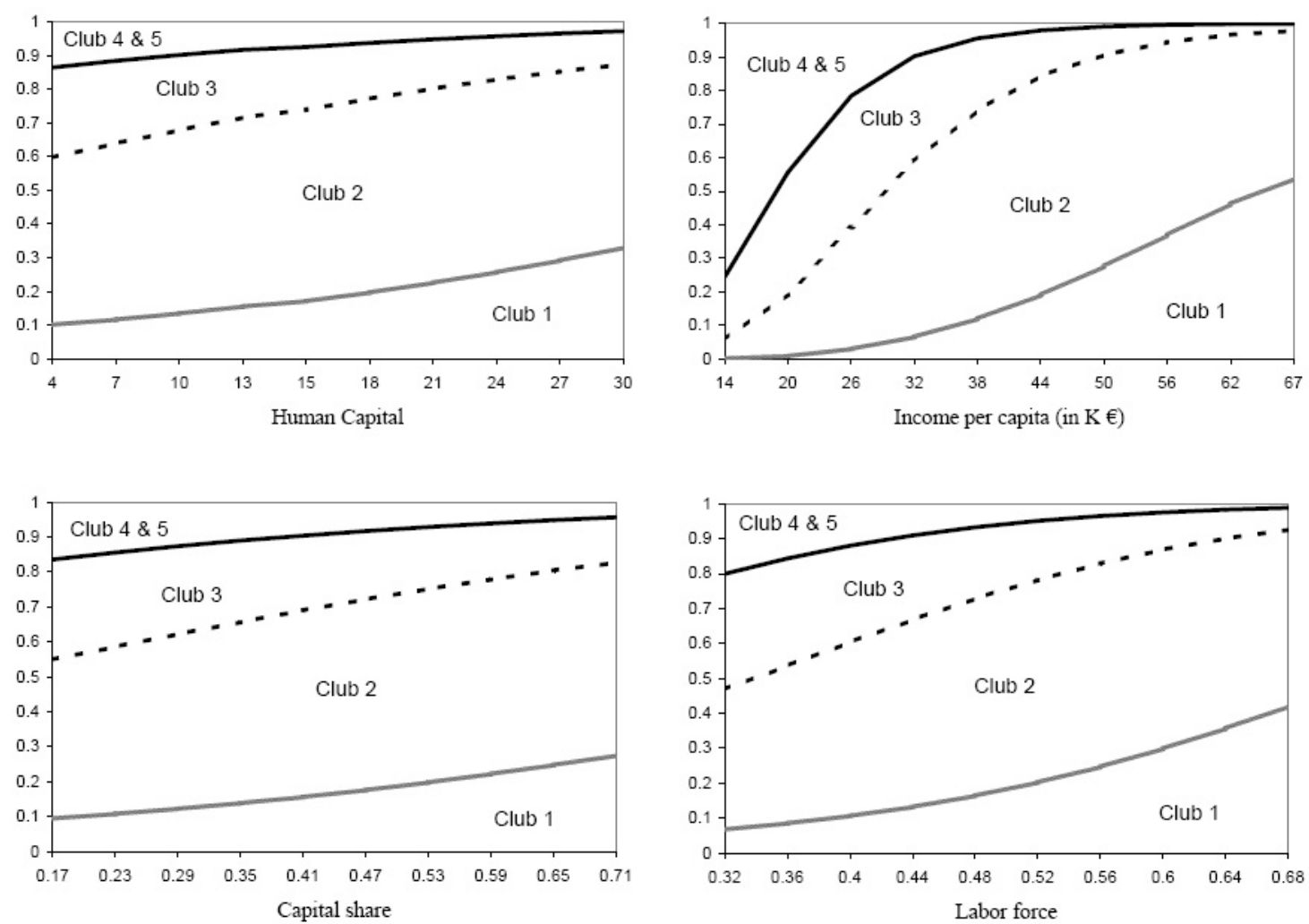

Figure 3: Cumulative probability for inititial conditions

club 2), while it decreases the probability of belonging to a low-income club, i.e., club $3 .^{11}$ Hence, we can conclude that the initial conditions explored by growth theory seem to be relevant in explaining the club formation of European NUTS 2 regions.

Concerning the partial derivatives with respect to the structural characteristics, the same broad picture arises. Apart from agglomeration, which has an insignificant effect, population growth and both technology variables have the expected positive influence on the probability of belonging to a high-income club. Interestingly, per worker income of neighboring regions seems to have a counterintuitive effect on club formation. In particular, an increase in a neighboring region's income tend to reduce a region's probability of belonging to club 1 and club 2, respectively. Although this is in contrast to expectations, a visual inspection of the map in figure 1 supports the estimation outcome. There, it can be seen that regions belonging to club 1 (mostly metropolitan areas) and club 2 are mainly surrounded by regions belonging to a club experiencing lower per worker income. This might be the result of backwash effects (Myrdal, 1957), i.e., regions from high-income clubs withdraw resources like labor or capital from their neighbors, where the latter consequently end up with a lower per worker income.

Finally, we explore how the probability of being a high-income (low-income) region changes when we vary the level of the initial conditions. Specifically, we consider each of the significant variables, i.e., human capital, income per worker, capital share and the labor force, holding the remaining variables constant. In figure 3 we plot the probabilities

\footnotetext{
${ }^{11}$ Note that, the sums of the estimated partial derivatives equal zero across the four clubs because the sums of the probabilities must always equal one.
} 
that the outcome is less than or equal to $c$ over the range of values of the respective variable, i.e., the probability of at least belonging to club $c$. For example, the lower line in the graphs shows the probability of belonging to club 1 when the value of the respective variable is altered. In general, all four graphs show the same pattern. The first graph reveals that regions with a high initial endowment of human capital, i.e., $30 \%$ of highly educated inhabitants, experience a $33 \%$ higher probabilitiy (from 0.6 to 0.8 ) of belonging to a high-income club (club 1 and club 2) than regions with a low initial endowment of human capital (4\%). The effect of initial confitions on the probability of converging to club 1 or 2 , is even more pronounced when it comes to per worker income. Regions that experienced a low income in the initial period, say 14,000 Euro, have a probability of only 0.08 to at least belong to the second income club, while regions with high per worker incomes, i.e., 67, 000 Euro, show a probabiltiy of 0.98 to converge to a high-income club. Summarizing, we can confirm that it is indeed initial conditions put forward by growth theory (e.g. Azeriadis and Drazen) that determine the path of convergence of European regions's per worker incomes. 


\section{Conclusion}

[to be completed]

Acknowledgments The authors gratefully acknowledge the grant no. P19025-G11 provided by the Austrian Science Fund (FWF). They thank Manfred M. Fischer for helpful suggestions. 


\section{A Appendix}

\section{A.1 Sample}

Our sample includes 206 NUTS $2^{12}$ regions in 17 countries, covering Austria (nine regions), Belgium (11 regions), Denmark (one region), Finland (five regions), France (22 regions), Western Germany (30 regions), Greece (13 regions), Italy (20 regions), Ireland (two regions), Luxembourg (one region), the Netherlands (12 regions), Norway (seven regions), Portugal (five regions), Spain (16 regions), Sweden (eight regions), Switzerland (seven regions) and the UK (37 regions).

Austria Burgenland; Niederösterreich; Wien; Kärnten; Steiermark; Oberösterreich; Salzburg; Tirol; Vorarlberg

Belgium Rêgion de Bruxelles-Capitale/Brussels Hoofdstedelijk Gewest; Prov. Antwerpen; Prov. Limburg (BE); Prov. Oost-Vlaanderen; Prov. Vlaams-Brabant; Prov. West-Vlaanderen; Prov. Brabant Wallon; Prov. Hainaut; Prov. Liège; Prov. Luxembourg (BE); Prov. Namur

Denmark Danmark

Finland Itä-Suomi; Etelä-Suomi; Länsi-Suomi; Pohjois-Suomi; Åland

France Île-de-France; Champagne-Ardenne; Picardie; Haute-Normandie; Centre; BasseNormandie; Bourgogne; Nord - Pas-de-Calais; Lorraine; Alsace; Franche-Comté; Pays de la Loire; Bretagne; Poitou-Charentes; Aquitaine; Midi-Pyrénées; Limousin; Rhône-Alpes; Auvergne; Languedoc-Roussillon; Provence-Alpes-Côte d'Azur; Corse

Germany Stuttgart; Karlsruhe; Freiburg; Tübingen; Oberbayern; Niederbayern; Oberpfalz; Oberfranken; Mittelfranken; Unterfranken; Schwaben; Bremen; Hamburg; Darmstadt; Gieen; Kassel; Braunschweig; Hannover; Lüneburg; Weser-Ems; Düsseldorf; Köln; Mnster; Detmold; Arnsberg; Koblenz; Trier; Rheinhessen-Pfalz; Saarland; Schleswig-Holstein

Greece Anatoliki Makedonia, Thraki; Kentriki Makedonia; Dytiki Makedonia; Thessalia; Ipeiros; Ionia Nisia; Dytiki Ellada; Sterea Ellada; Peloponnisos; Attiki; Voreio Aigaio; Notio Aigaio; Kriti

Italy Provincia Autonoma Bolzano/Bozen \& Provincia Autonoma Trento; Piemonte; Valle d'Aosta/Vallée d'Aoste; Liguria; Lombardia; Veneto; Friuli-Venezia Giulia; Emilia-Romagna; Toscana; Umbria; Marche; Lazio; Abruzzo; Molise; Campania; Puglia; Basilicata; Calabria; Sicilia; Sardegna

Ireland Border, Midland and Western; Southern and Eastern

Luxembourg Luxembourg (Grand-Duché)

\footnotetext{
${ }^{12}$ Nomenclature of Statistical Territorial Units
} 
Netherlands Groningen; Friesland; Drenthe; Overijssel; Gelderland; Flevoland; Utrecht; Noord-Holland; Zuid-Holland; Zeeland; Noord-Brabant; Limburg (NL)

Norway Oslo og Akershus; Hedmark og Oppland; Sør-Østlandet; Agder og Rogaland; Vestlandet; Trøndelag; Nord-Norge

Portugal Norte; Algarve; Centro (PT); Lisboa; Alentejo

Spain Galicia; Principado de Asturias; Cantabria; País Vasco; Comunidad Foral de Navarra; La Rioja; Aragón; Comunidad de Madrid; Castilla y León; Castilla-La Mancha; Extremadura; Cataluña; Comunidad Valenciana; Illes Balears; Andalucía; Región de Murcia

Sweden Östra Mellansverige; Sydsverige; Norra Mellansverige; Mellersta Norrland; Övre Norrland; Småland med öarna; Västsverige

Switzerland Région lémanique; Espace Mittelland; Nordwestschweiz; Zürich; Ostschweiz; Zentralschweiz; Ticino

United Kingdom Tees Valley and Durham; Northumberland and Tyne and Wear; Cumbria; Cheshire; Greater Manchester; Lancashire; Merseyside; East Riding and North Lincolnshire; North Yorkshire; South Yorkshire; West Yorkshire; Derbyshire and Nottinghamshire; Leicestershire, Rutland and Northamptonshire; Lincolnshire; Herefordshire, Worcestershire and Warwickshire; Shropshire and Staffordshire; West Midlands; East Anglia; Bedfordshire and Hertfordshire; Essex; Inner London; Outer London; Berkshire, Buckinghamshire and Oxfordshire; Surrey, East and West Sussex; Hampshire and Isle of Wight; Kent; Gloucestershire, Wiltshire and North Somerset; Dorset and Somerset; Cornwall and Isles of Scilly; Devon; West Wales and the Valleys; East Wales; North Eastern Scotland; Eastern Scotland; South Western Scotland; Highlands and Islands; Northern Ireland

\section{A.2 Clustering algorithm for club convergence identification}

If the null hypothesis of the overall convergence is rejected, test for club convergence should be applied, as presented by Phillips and Sul (2007). It consists of the following steps:

Step 1: Cross-section ordering by final observation

Convergence, also within clubs, as $T \rightarrow \infty$ is usually most evident in the final time series observations. The units of the cross-section should be sorted in the descending order due to the last period in the time series dimension of the panel. In case of significant volatility in $X_{i t}$, the sorting can be done according to the time series average over the last $1 / 2$ or $1 / 3$ periods of the time dimension.

Step 2: Formation of core group of $k^{*}$ regions

Take the first $k$ units (with $2 \leq k<N$ ) from the panel, run the $\log t$ regression. If $t_{\hat{b}}$ for this $k$ units is larger than -1.65 , add further units one by one and every time calculate $t_{\hat{b}}$ 
for the $k$ selected units. Continue as long as the $t_{\hat{b}}$ is increasing and larger than -1.65 (at $5 \%$ significance level). After obtaining a smaller value of $t_{\hat{b}}$ conclude that the core group with $k^{*}=k-1$ members of a club is formed. If $t_{\hat{b}}>-1.65$ does not hold for the first two units, drop the first unit and run the $\log t$ regression for the second and third unit. Continue until finding a pair of units with $t_{\hat{b}}>-1.65$. If there are no such units in the whole sample, conclude that there are no convergence clubs in the panel.

\section{Step 3: Sieve the data for new club members}

After identifying the core group of a club, conduct a test for club membership of other units in the panel. Add one of the remaining units at a time to the $k^{*}$ members of the core group and run the $\log t$ regression. Repeat for all the units outside the core group. Select units with $t_{\hat{b}}>c$, with $c$ being a critical value $(c \geq 0)$ and add them to the core group. Run the $\log t$ test for the whole group. If $t_{\hat{b}}>-1.65$, conclude that this group constitutes a convergence club. Otherwise increase the critical value for the club membership selection, form a new group consisting of the core group and all the units with $t_{\hat{b}}$ larger than the increased critical value, and run the $\log t$ regression. Repeat till finding $t_{\hat{b}}>-1.65$ for the whole group. Then conclude that those units form a convergence club. If there are no units apart from the core group that result in $t_{\hat{b}}>-1.65$, conclude that a convergence club consists only of the core group.

\section{Step 4: Recursive and stopping rule}

Form a second group from all the units outside the convergence club, i.e., with $t_{\hat{b}}<c$. Run the $\log t$ test for the whole group to check whether $t_{\hat{b}}>-1.65$ and the group converges. If not, repeat Steps 1-3 on this group to determine whether there is a smaller subgroup that forms a convergence clubs in the panel. If there is no $k$ in Step 2 for which $t_{b}>-1.65$, conclude that the remaining units diverge.

\section{A.3 Test for merging}

Phillips and Sul (2009) suggest the following test for merging between the groups that are formed according to the clustering algorithm described in appendix A.2: take the first and the second group and run the $\log t$ test, if the t-statistic is larger than -1.65 (5\% significance level) assume that both groups form a club together, repeat the test after adding the next group, continue until the t-statistic indicates that the convergence hypothesis is rejected. Conclude that all the groups but the last one converge and start the test again from the group for which the convergence hypothesis was rejected. 


\section{References}

Anselin, Luc 1988 Spatial Econometrics: Methods and Models. Kluwer, Dordrecht.

Azariadis, Costas, Drazen, Allan 1990. Threshold externalities in economic development. Quarterly Journal of Economic Development 105(2): 501-526.

Barro, Robert J., Sala-i-Martin, Xavier 1991. Convergence across states and regions. Brookings Papers on Economic Activity 22(1): 107-182.

Bernard, Andrew B., Durlauf, Steven N. 1995. Convergence in international output . Journal of Applied Econometrics 10(2): 97-108.

Burkhauser, Richard V., Cutts, Amy Crews, Daly, Mary C., Jenkins, Stephen P. 1999. Testing the significance of income distribution changes over the 1980s business cycle: A cross-national comparison. Journal of Applied Econometrics 14(3): 253-272.

Canova, Fabio 2004. Testing for convergence clubs in income per capita: a predictive density approach. International Economic Review 45(1): 49-77.

Corrado, Luisa, Martin, Ron, Weeks, Melvyn 2004. Identifying and interpreting regional convergence clusters across Europe. Economic Journal 115(502): C133-C160.

Dall'erba, Sandy, Le Gallo, Julie 2008. Regional convergence and the impact of European Structural Funds over 1989-1999: a spatial econometric analysis. Papers in Regional Science 87(2): 219-244.

Deardorff, Alan V. 2001. Rich and Poor Countries in Neoclassical Trade and Growth. The Economic Journal 111: 277-294.

Desdoigts, Alain 1999. Patterns of economic development and the formation of clubs. Journal of Economic Growth 4(3): 305-330.

Durlauf, Steven N., Johnson, Paul A. 1995. Multiple regimes and cross-country growth behaviour. Journal of Applied Econometrics 10(4): 365-384.

Galor, Oded 1996. Convergence? Inferences from theoretical models. Economic Journal 106(437): 1056-1069.

Getis, Arthur 1995. Spatial filtering in a regression framework: examples using data on urban crime, regional inequality, and government expenditures. In New Directions in Spatial Econometrics, ed. Luc Anselin and Raymond J.G.M. Florax. Springer Verlag, Berlin Heidelberg New York.

Getis, Arthur, Griffith, Daniel A. 2002. Comparative spatial filtering in regression analysis. Geographical Analysis 34(2): 130-140.

Getis, Arthur, Ord, J. Keith 1992. The analysis of spatial association by use of distance statistics. Geographical Analysis 24(3): 189-206. 
Greene, William H. 2000 Econometric Analysis. Prentice Hall International, Inc.

Hobijn, Bart, Franses, Philip H. 2000. Asymptotically perfect and relative convergence of productivity. Journal of Applied Econometrics 15(1): 59-81.

Hodrick, Rober James, Prescott, Edward C. 1997. U.S. business cycles: an empirical investigation. Journal of Money, Credit and Banking 29(1): 1-16.

Islam, Nazrul 2003. What have we learnt from the convergence debate? Journal of Economic Surveys 17(3): 309-362.

Long, J. Scott 1997 Regression Models for Categorical and Limited Dependent Variables. Sage Publications, London.

Martin, Philippe, Ottaviano, Gianmarco P. I. 2001. Growth and agglomeration. International Economic Review 42(4): 947-968.

McKelvey, Richard D., Zavoina, William 1975. A Statistical model for the analysis of ordinal level dependent variables. Journal of Mathematical Sociology 4: 103-120.

Mora, Toni 2005. Evidencing European regional convergence clubs with optimal grouping criteria. Applied Economics Letters 12(15): 937-940.

- 2008. Factors conditioning the formation of European regional convergence clubs. Annals of Regional Science 42(4): 911-927.

Myrdal, Gunnar 1957 Economic Theory and Underdeveloped Regions. Gerald Duckworth, London.

Phillips, Peter C.B., Sul, Donggyu 2007. Transition modeling and econometric convergence tests. Econometrica 75(6): 1771-1855.

_ forthcoming. Economic transition and growth. Journal of Applied Econometrics.

Quah, Danny 1996a. Empirics for economic growth and convergence. European Economic Review 40: 1353-1375.

- 1996b. Regional convergence clusters across Europe. European Economic Review 40: 951-958.

Solow, Robert M. 1956. A contribution to the theory of economic growth. Quarterly Journal of Economics 70(1): 65-94. 